\title{
MAPEAMENTO E AVALIAÇÃO DA COBERTURA VEGETAL DO DISTRITO DO CAMBUCI (CENTRO DE SÃO PAULO/SP)
}

\author{
Mariana Mara Morena Gomes
}

\section{Oriana A. Fávero}

RESUMO: O conflito entre ambiente e desenvolvimento nas áreas urbanas é intenso e visível nos projetos de desenvolvimento urbano, os quais não dão a devida importância para a sustentabilidade ecológica. A qualidade ambiental se tornou de grande relevância no século atual, devido a intensa dinâmica populacional e o modo de vida consumista, que intensifica a degradação do meio ambiente natural. Deste modo, é importante se indicar o padrão de qualidade ambiental urbana. A cobertura vegetal é considerada um importante indicador para avaliação da qualidade ambiental possuindo benefícios diretos e indiretos para a qualidade do ar e como amenizador térmico. Considerando a importância da cobertura vegetal nas áreas urbanas, o presente trabalho teve como objetivo contribuir com estudos de qualidade ambiental urbana por meio do mapeamento, quantificação e caracterização da cobertura vegetal do Distrito do Cambuci no Centro de São Paulo/SP. O mapeamento foi realizado com a utilização de fotos aéreas da área com escala 1:6.000 cedidas pelo Prefeitura de São Paulo, para a construção de um mosaico. Foi realizado o método "overlay", e posteriormente foi realizada a redução para alcançar a escala de 1:10.000, e com o auxilio de um papel vegetal milimetrado foi quantificado a área de cobertura vegetal do Distrito. Verificou-se um índice de cobertura vegetal de $8,64 \%$. Na área foi verificada uma vegetação fragmentada e descontínua, com algumas grandes áreas sem vegetação. Deste modo, foi caracterizado como uma área com pouca vegetação que influencia nos aspectos climáticos e na qualidade ambiental e de vida da área.

Palavras chave: Cobertura Vegetal. Distrito do Cambuci. Qualidade Ambiental. 


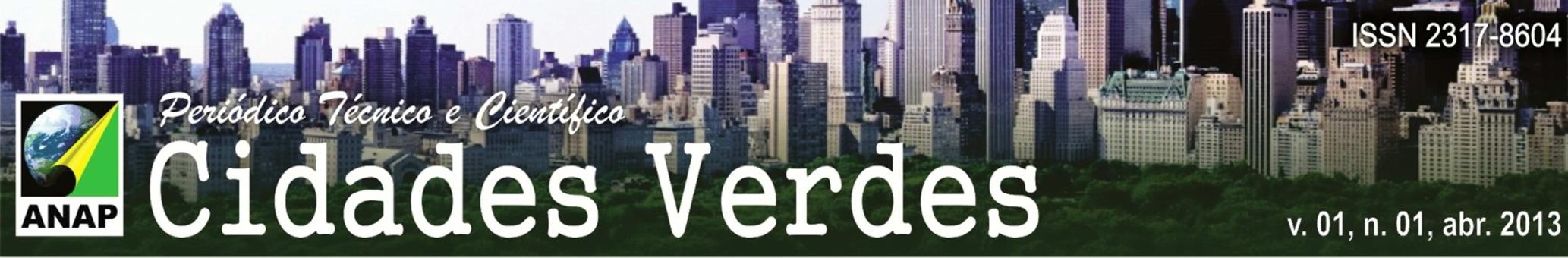

\section{INTRODUÇÃO}

A expansão constante de áreas urbanas constituídas tanto pelo crescimento horizontal quanto pelo vertical em altos prédios tem causado consideráveis modificações na paisagem natural, deteriorando os recursos naturais como solo, água, ar e organismos, comprometendo a qualidade do ambiente (BUCCHERI FILHO. e NUCCI, 2006).

O crescimento da urbanização teve uma grande ascensão durante o século XIX, e este crescimento vem se destacando com o passar do tempo, caracterizando hoje o modo de vida da população do planeta. Grande parte da população mundial vive em áreas de aglomeração urbana (GOMES e SOARES, 2004).

Segundo SCHMIDT et al. (2005) nos tempos de hoje o uso da terra tem sido planejado com base nos avanços econômicos, menosprezando a importância que o meio físico tem para a sobrevivência da sociedade. A população se beneficia com os elementos culturais e sociais que as cidades oferecem, mas a qualidade ambiental urbana se apresenta em declínio por consequência da poluição do ar e sonora, escassez de espaços livres públicos e pouca quantidade de vegetação urbana.

O conflito entre ambiente e desenvolvimento nas cidades é intenso e visível nos projetos de desenvolvimento urbano, os quais não dão a devida importância para a sustentabilidade ecológica que propõe um desenvolvimento sem a alteração negativa do meio ambiente. (SCHMIDT et al., 2005).

Por consequência da intensa urbanização dos municípios, a área de terra já muito utilizada para construções só permite ocupações novas de construções de edifícios de vários andares, caracterizando uma verticalização da urbanização causando assim inúmeros problemas para o ambiente e clima da área (SCHMIDT et al., 2005).

Manter um elevado padrão de qualidade ambiental pode ser considerado uma missão de grande dificuldade, pois as situações das cidades atuais, principalmente em países "subdesenvolvidos" como o Brasil, se caracterizam por apresentarem um processo de urbanização desenfreada e que permanecem em evolução de maneira exacerbada, constituindo uma desordem seguida de problemas sociais (GOMES e SOARES, 2004). 
Por outro lado, já é consenso que o crescimento de cidades afetam certos fatores ambientais que alteram drasticamente seu clima influenciando os aspectos físicos, sociais e biológicos da área. Podem se destacar os seguintes fatores: a alta densidade demográfica acumulando grandes populações em pequenas áreas; grande quantidade de áreas construídas; pavimentação do solo e intensa atividade industrial (LOMBARDO, 1985 apud GOMES e SOARES, 2004).

Existem variáveis que podem indicar o padrão de qualidade ambiental de um determinado espaço, as quais são muito discutidas por serem consideradas diferentemente por diversos autores. Dependem da concepção de cada cidadão, pesquisador e planejador urbano para que tais variáveis sejam valorizados ou não no planejamento do meio ambiente urbano (GOMES e SOARES, 2004).

A cobertura vegetal é considerada como indicador, instrumento e parâmetro de avaliação da qualidade ambiental urbana (NUCCI e CAVALHEIRO, 1999; GOMES E SOARES, 2004; NUCCI, 2008). O levantamento da cobertura vegetal tem grande importância de âmbito público em geral, pois permite um entendimento fácil dos índices que podem ser comparados entre cidades e bairros, com a função de avaliação ambiental (DIAS, 2002 apud BUCCHERI FILHO e NUCCI, 2006).

Caracterizando o conceito de cobertura vegetal, pode-se dizer que são as projeções da vegetação em mapas visualizadas e identificadas por fotografias aéreas sem auxílio da estereocopia (ou olho nu). A escala da foto, utilizada para o mapeamento, deve acompanhar a localização da cobertura e devem ser destacadas as manchas desta vegetação. $\mathrm{Na}$ análise de cobertura vegetal é considerada toda vegetação existente nos sistemas urbanos e todas as vegetações encontradas nas Unidades de Conservação (CAVALHEIRO et al., 1999; NUCCI, 2008).

Segundo Freitas e Lombardo (2008) a cobertura vegetal urbana é imprescindível em toda área da cidade com a função de reguladora climática possuindo benefícios diretos e indiretos para a qualidade do ar e como amenizador térmico na área urbana.

Além disso, proporciona influência direta na saúde física e mental da população, constituindo assim, as "áreas verdes" públicas inseridas no meio urbano, uma porção imprescindível para o bem estar de cada cidadão (LOBODA; DE ANGELIS, 2005). De 


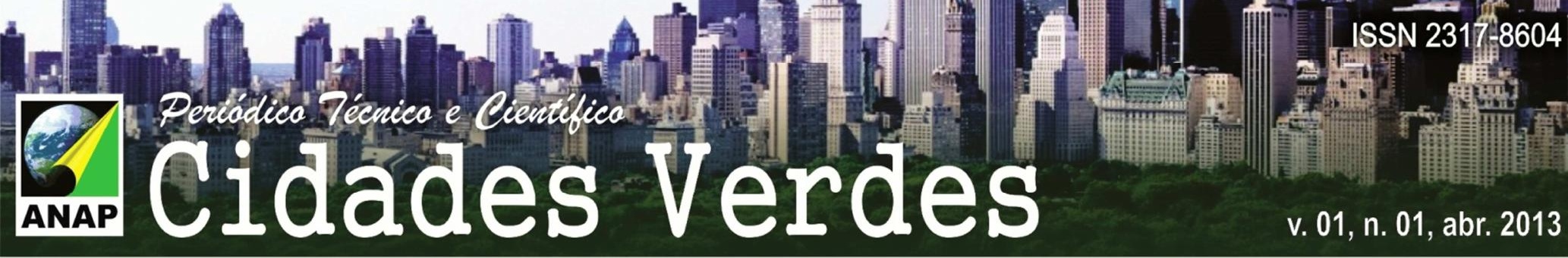

acordo com Motloch (1991 apud SCHWETS; BROWN, 1999) as árvores são elementos essenciais para as paisagens, pois são instrumentos que caracterizam o lugar como paisagem e ainda podem contribuir com o valor econômico da área.

A urbanização vem causando grandes alterações climáticas. Segundo Marcus e Detwyler (1972 apud NUCCI, 1999; 2008) as mudanças mais relevantes estão relacionadas com a diminuição da umidade relativa do ar, da velocidade do vento e da radiação solar no solo; contudo há o aumento da temperatura, da poluição e da precipitação.

Além dessas mudanças, a urbanização traz outras consequências ambientais tais como: aumento da impermeabilização do solo devido à ocupação do mesmo por concreto, pressionando os corpos d'água e espaços livres a ocuparem pequenos espaços, e a verticalização que acarreta o aumento da capacidade térmica, levando assim a diminuição da evaporação, trazendo um aumento térmico na área. Todos esses procedimentos são os principais fenômenos para se determinar uma 'ilha de calor', muito frequentes em grandes metrópoles (LOMBARDO, 1985 apud NUCCI, 2008).

Como já foi apresentada, a qualidade de vida nas áreas urbanas está diretamente ligada à infraestrutura, desenvolvimento econômico-social e questões ambientais da cidade. Em relação ao fator ambiental é importante destacar a função das "áreas verdes" públicas para o bem estar da população, influenciando na saúde física e mental da população (LOBODA e DE ANGELIS, 2005).

Um dos procedimentos para a realização da caracterização da cobertura vegetal, visando realizar estudo e mapeamento da mesma, segundo principalmente Nucci e Cavalheiro (1999) e Nucci (2008) é a identificação da cobertura vegetal em fotos aéreas sem auxílio de estereoscopia, sendo este um procedimento mais simples e de custo econômico mais baixo. De acordo com Nucci (1999) para o correto procedimento de mapeamento deve-se quantificar a cobertura vegetal sendo acompanhada de sua configuração.

Jim (1989) apresentou uma proposta de classificação para a distribuição da vegetação urbana de Hong Kong que abrange especificamente a cobertura vegetal arbórea nestas áreas. Usando atributos como as formas das manchas de cobertura 
vegetal elaboraram critérios de classificação do que denominou 'tree-canopy cover characteristics' (Figura 01). Esta classificação consiste em três categorias diferentes (Isolated, Linear e Connected), sendo cada uma subdividida em três subcategorias.

Primeiramente a categoria Isolated caracterizada em apresentar muitas áreas edificadas, com ruas e outras superfícies impermeáveis. As árvores se localizam principalmente de modo espalhado, apertadas em calçadas e podendo aparecer em pequenos jardins de residências privadas. Divide-se em (JIM, 1989): Dispersed: consiste em pequenas unidades semelhantes, árvores solitárias situadas em matrizes edificadas; Clustered: poucas árvores entre corpos edificados; Clumped: grande quantidade de árvores agregadas em quintais ou taludes.

As sub-categorias do tipo Linear consistem em uma justaposição de árvores em direção à orientação em alongados habitats artificiais, divididas em: Rectilinear: alinhamento estreito de árvores das calçadas, vegetação na periferia de lotes; Curvilinear: seguimentos largos adjacentes às ruas, podendo ocorrer florestas pré-existentes; Annular: caso de variantes curvilíneas, vegetação formando círculos contínuos como anéis, ao redor de pequenas elevações, também ocorrem florestas pré-existentes.

Por fim o tipo Connected, formado por uma ampla cobertura vegetal com alto grau de conectividade e continuidade, localizada em terrenos com elevada declividade ou nas bordas da cidade. Reticulate: vegetação em redes alongadas atravessando vertentes não urbanizadas e locais com construção agrupada; Ramified: apresentando mais de 50\% da área constituída por cobertura vegetal contínua, podendo envolver áreas edificadas; Continuous: consiste em $75 \%$ da área com cobertura vegetal, sendo representadas por florestas na periferia da cidade com uma pequena taxa de urbanização na área. 


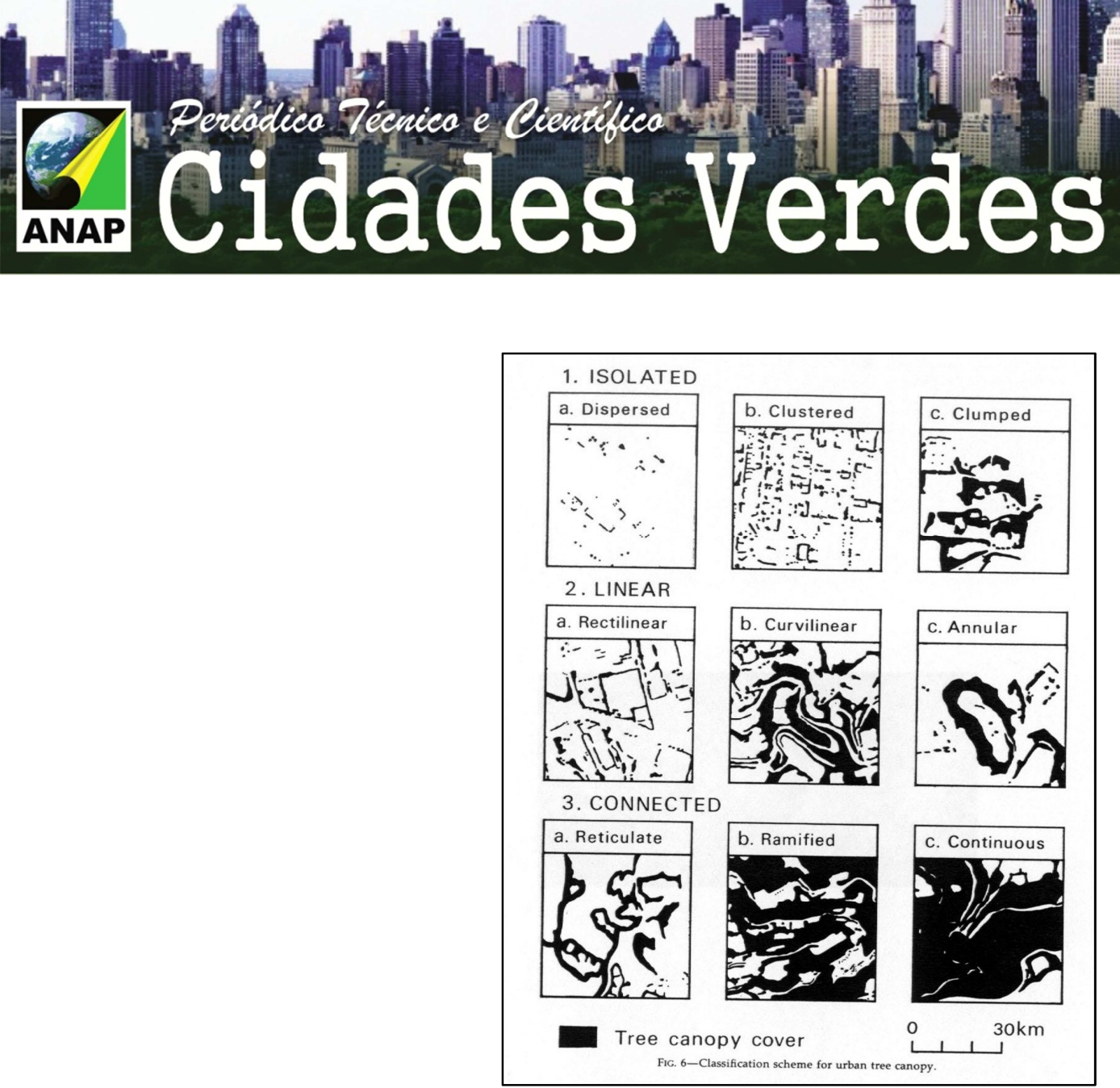

Figura 01 - Modelo de classificação da cobertura vegetal (fonte: Jim, 1989)

A importância da classificação e caracterização das coberturas das copas de árvores da vegetação urbana reside em seu potencial de contribuição para 0 entendimento de suas relações com a matriz construída, oferecendo uma estrutura para estudos comparativos e sistemáticos sobre a cobertura vegetal urbana (JIM, 1989).

A qualidade ambiental também depende de uma determinada quantidade de cobertura vegetal em uma área urbanizada. Apesar de haver algumas controvérsias, segundo autores, o índice de cobertura vegetal na faixa de 30\% é satisfatório para proporcionar um adequado balanço térmico (OKE, 1973 apud NUCCI, 2008), e índice inferior a $5 \%$ caracteriza-se um ambiente que apresenta semelhanças climáticas e florísticas de um deserto (LOMBARDO, 1985 apud VENTURA e FÁVERO, 2005; NUCCI, 2008).

Para um planejamento que prioriza a qualidade ambiental os elementos fundamentais a serem considerados são: os espaços livres, áreas verdes e cobertura vegetal. O poder público, responsável por esse planejamento, deve criar, auxiliar e manter 
ambientes agradáveis, dentro de padrões para uma qualidade de vida saudável para os cidadãos, fornecendo assim áreas para lazer (BUCCHERI FILHO; NUCCI, 2006).

Além disso, estes elementos tem importância para suprir necessidades das pessoas estarem próximas de áreas com natureza mesmo dentro de uma cidade grande, que não demande longa locomoção para estar em ambientes com vegetação intensa (BUCCHERI FILHO; NUCCI, 2006).

Deste modo, fica explícita a importância da cobertura vegetal para a qualidade de vida nas cidades. Porém, dificuldades na definição de termos associados com a quantificação de áreas vegetais, retardam as iniciativas de critérios mais corretos para a elaboração de leis de defesa da qualidade de vida urbana no que se trata da cobertura vegetal (NUCCI; CAVALHEIRO, 1999).

\section{MATERIAIS E MÉTODOS}

\section{Localização e Breve Caracterização da Área de Estudo}

A área de estudo deste trabalho é o Distrito do Cambuci, situado na zona central da cidade de São Paulo, sob administração da Subprefeitura da Sé, juntamente com os Distritos da Bela vista, Bom Retiro, Consolação, Liberdade, República, Santa Cecília e Sé, fazendo divisa com Mooca, Ipiranga e Vila Mariana, os quais não fazem parte da administração da Sé. Como delimitação pode-se considerar ao Sul a Rua Coronel Diogo, ao Norte Rua da Mooca, a Oeste a Avenida Lacerda Franco, e a Leste as Ruas Gaspar Fernandes, Leandro de Carvalho e Engenheiro Ari Cajado e a Linha Ferroviária na altura da estação da Mooca, conforme mostra a Figura 02.

Segundo dados da Prefeitura de São Paulo, no censo de 2010 o Distrito do Cambuci apresenta 36.948 habitantes distribuídos em 3,9 Km², sendo assim a densidade demográfica é de 9,474 hab./Km². Como características econômicas o Distrito é habitado por cidadãos com renda familiar que gira em torno de $R \$ 1.958,00$. Considerando o perfil socioeconômico o Distrito está classificado em $18^{\circ}$ lugar entre os distritos da cidade de São Paulo (TAKIYA, 2002). 
Por ser uma região de fácil acesso e bem próxima à região central da cidade, o Cambuci passou por um processo de construção de fábricas e oficinas. Assim foram construídas indústrias consideradas na época de grande porte nas áreas propicias e planas do bairro. Essas construções valorizaram-se também por áreas de fácil acesso pelas linhas de bonde de tração animal que havia no bairro (PINOTTI, 2006).

A partir das primeiras décadas do século 20 as ruas do Cambuci foram lentamente substituídas por calçamento com iluminação e até linha de bonde. Foi intensificado o número de fábricas, e o comércio teve um rápido crescimento que fez com que o distrito fosse conhecido por toda a cidade de São Paulo (PONCIANO, 2002). Tal crescimento foi ativo a partir do centro do bairro, o Largo do Cambuci, e através das ruas mais importantes, constituindo assim corredores principais da área (PINOTTI, 2006).

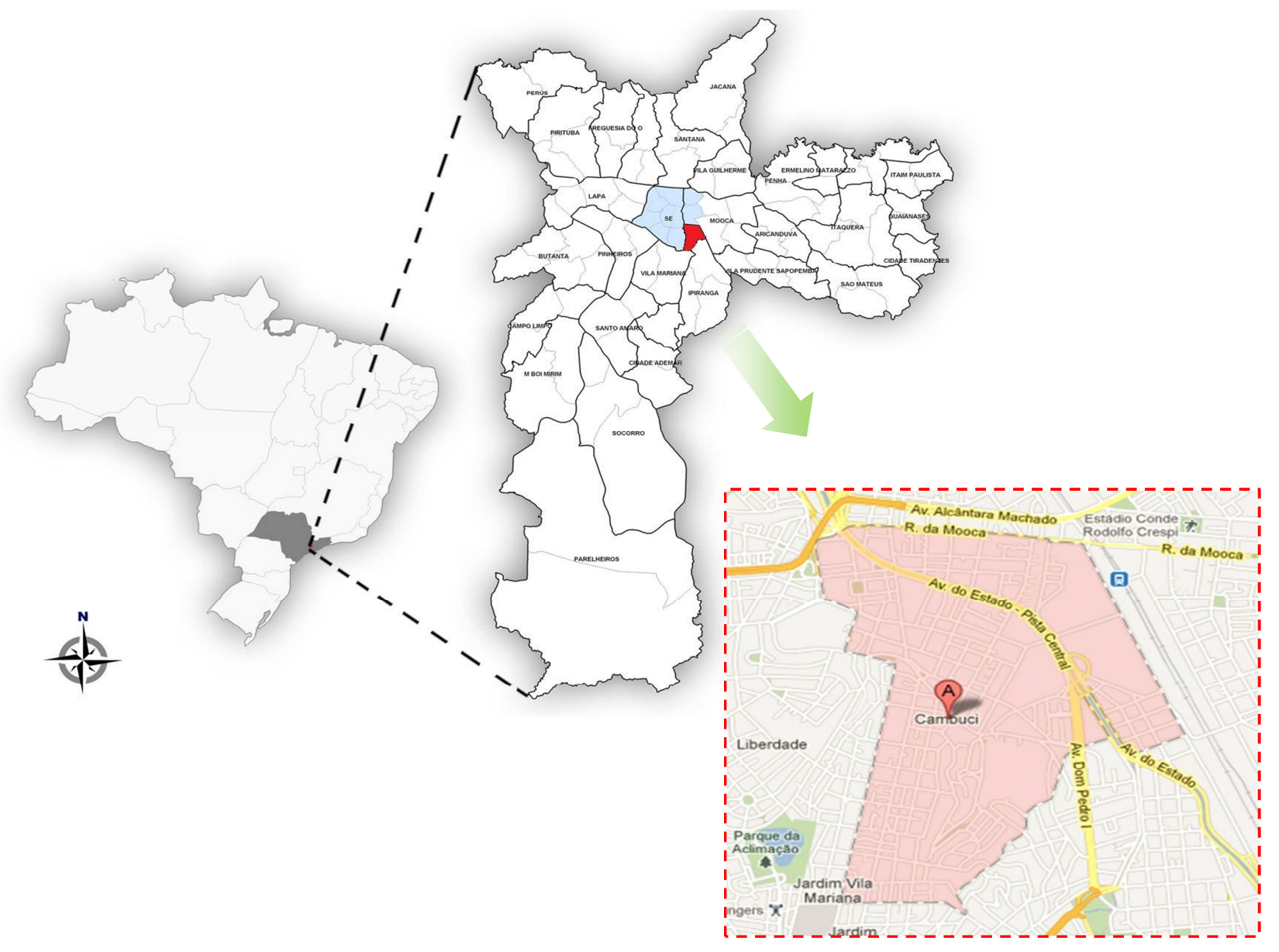




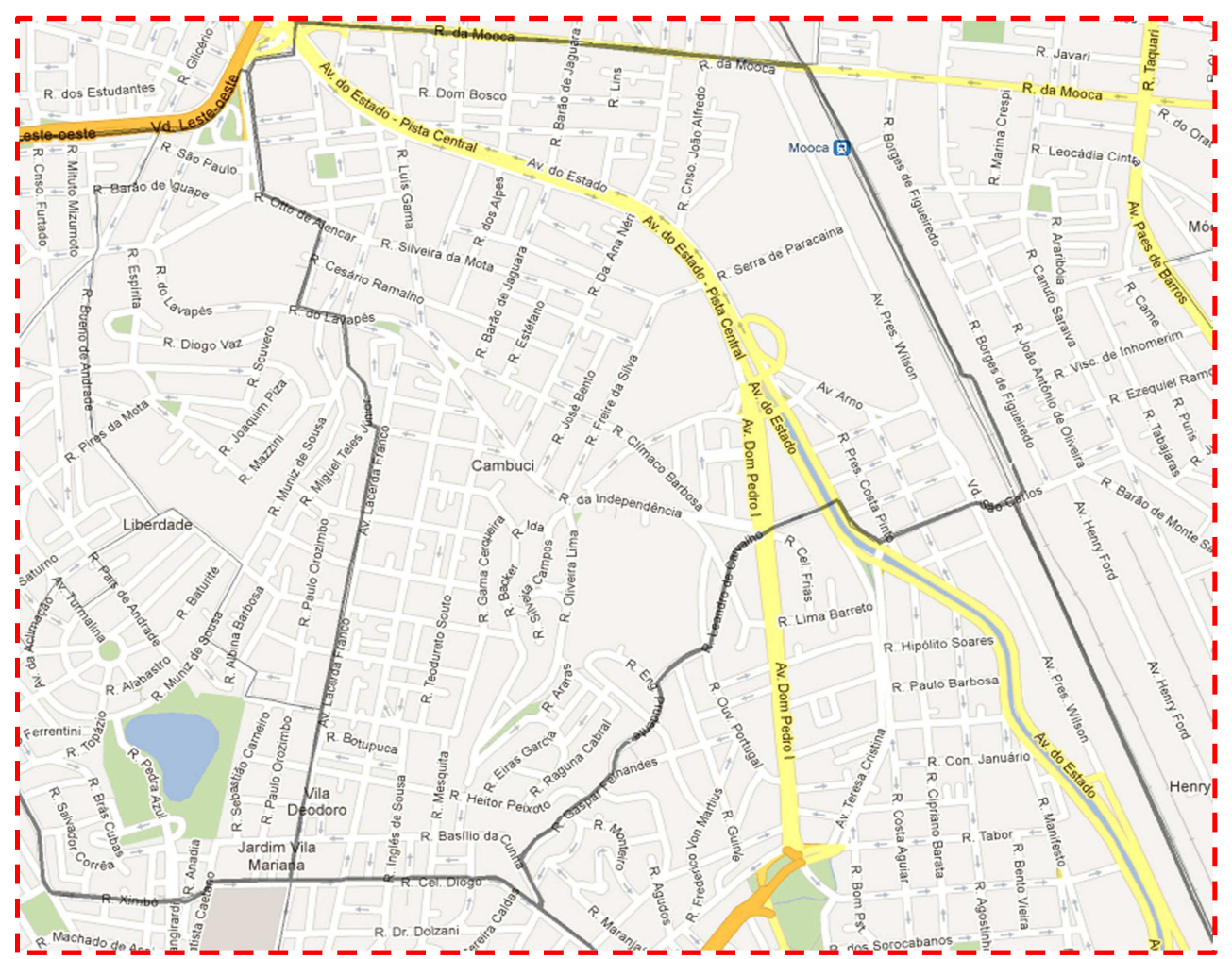

Figura 02 - Croquis de localização do Distrito do Cambuci com destaque de ruas e principais pontos de referência (Fonte: http://infolocal.prefeitura.sp.gov.br/mapa.php, Acesso em 09 de setembro de 2012; Org: Fávero, 2012).

\section{Procedimentos}

A primeira fase do trabalho constituiu na realização de um levantamento de estudos relacionados a conceitos e métodos de avaliação da qualidade ambiental urbana com base na vegetação, obtidos de diversos autores, realizando comparação entre eles para um desenvolvimento coerente tanto do conteúdo teórico como metodológico do trabalho.

Foram obtidas fotos aéreas na escala 1: 6.000 na Secretaria da Habitação da Prefeitura de São Paulo, correspondentes à área do distrito. Tais imagens foram realizadas por meio de sobrevoo programado que mantém na mesma altura relativa em que o avião segue em linha reta com velocidade constante, no ano de 2000. 


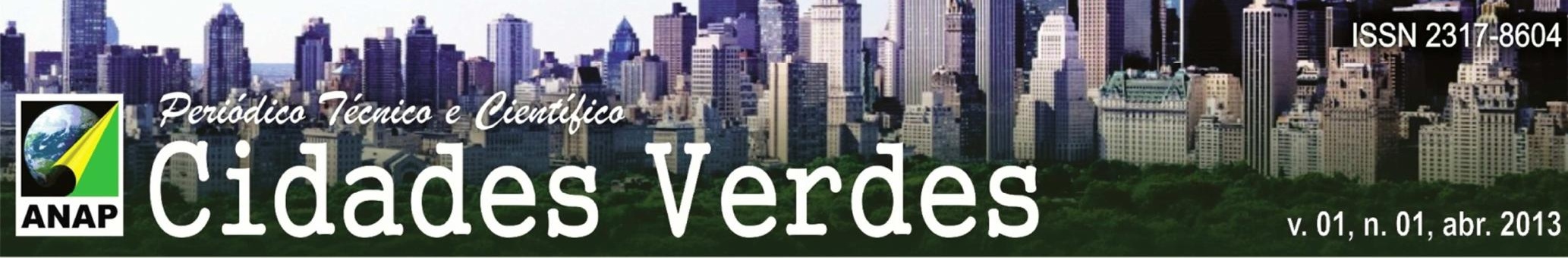

Para a realização do mapeamento da cobertura vegetal da área de estudo, foi feita a composição de mosaico com as fotos aéreas, no qual a área está contida, com nove aerofotos. Cada foto apresentou uma área de sobreposição com a outra foto 'vizinha', e deste modo as fotos foram encaixadas, compondo uma imagem total do distrito.

Para a realização do mapeamento da cobertura vegetal utilizou-se o método "overlay", que consiste na passagem de informações da imagem do mosaico, utilizando caneta (no caso retroprojetor) em uma folha de material transparente, sendo no caso utilizado acetato.

Foram atribuídas "texturas" diferentes para distinguir vegetação arbórea e vegetação herbáceo-arbustiva na área, preenchendo de preto com a caneta de retroprojetor áreas identificadas como copas de árvores altas que tinham coloração verde escuro nas fotos, e hachuras, para vegetações com arbustos e herbáceas, caracterizadas nas fotos com coloração esverdeada mais clara.

Nas fotos, devido à ação da luz do sol, vários pontos apresentaram sombreamento de prédios que podiam ser confundidas com copas de árvores. Para uma melhor interpretação dessas áreas foram utilizadas visualizações de imagens de sensoriamento remoto disponíveis no programa Google Earth (É um programa com a função de apresentar a superfície terrestre de modo tridimensional. A partir de mosaico de imagens de satélite, GIS 3D e imagens obtidas por aeronaves), para permitir a elucidação de dúvidas em relação à existência de vegetação nas áreas sombreadas.

Após a realização completa do mapeamento, foi realizada a redução do mapa em folha de acetato por meio de fotocópias com redução a cerca de $40 \%$. Este procedimento foi de grande importância, pois desse modo o mapa atingiu a escala de 1:10.000, o que permitiu a comparação com outros trabalhos relacionados ao estudo de cobertura vegetal urbana que adotaram esta mesma escala.

Foi realizada a quantificação da área do distrito e a das áreas das respectivas categorias de cobertura vegetal com o auxílio de papel vegetal milimetrado sobreposto ao mapa reduzido, contando os $\mathrm{mm}^{2}$ das áreas mapeadas. Dessa forma foi possível obter a porcentagem de cobertura vegetal do distrito. 
Por fim, segundo a configuração da cobertura vegetal e manchas de vegetação do mapa, foi realizada a classificação de sua distribuição conforme as propostas de Jim (1989).

\section{RESULTADOS E DISCUSSÕES}

Conforme a quantificação realizada no mapa (Figura 03) e detalhada na Tabela 01 verificou-se que o Distrito do Cambuci é constituído por $5,1 \mathrm{Km}^{2}$ de área total dos quais $448.700 \mathrm{~m}^{2}$ (8,64\% da área do distrito) são ocupados por cobertura vegetal, divididos em $322.800 \mathrm{~m}^{2}(6,28 \%)$ de vegetação arbórea e $125.900 \mathrm{~m}^{2}$ (2,45\%) de vegetação herbáceoarbustiva. No mapa, foram usadas texturas diferentes para diferenciar cada tipo de vegetação: arbórea incluindo árvores de médio e grande porte que foram identificadas nas fotos por coloração esverdeada escura; vegetação herbáceo-arbustiva caracterizada nas imagens com verde claro, são vegetações mais baixas, como gramados e pequenos arbustos.

Destaca-se ainda da quantificação, que dos $8,6 \%$ da área do Distrito que apresenta cobertura vegetal (CV), a vegetação arbórea contém $71,95 \%$ do total da cobertura e a vegetação herbáceo-arbustiva corresponde a $28,05 \%$ da CV.

Tabela 1 - Quantificação da cobertura vegetal do Distrito do Cambuci

\begin{tabular}{|c|c|c|c|c|c|}
\hline \multirow{2}{*}{ Atributos Analizados } & \multirow{2}{*}{$\begin{array}{l}\text { Mapa } \\
\left(\mathrm{mm}^{2}\right)\end{array}$} & \multicolumn{2}{|c|}{ Realidade } & \multicolumn{2}{|c|}{$\%$} \\
\hline & & $\left(m^{2}\right)$ & $\left(\mathrm{Km}^{2}\right)$ & Área & $\mathrm{CV}$ \\
\hline Área de estudo & 51.376 & 5.137 .600 & 5,13 & 100 & - \\
\hline $\begin{array}{l}\text { Cobertura Vegetal } \\
\text { (CV) }\end{array}$ & 4.487 & 448.700 & 0,45 & 8,64 & 100 \\
\hline $\begin{array}{c}\text { Cobertura Vegetal } \\
\text { Arbórea }\end{array}$ & 3.228 & 322.800 & 0,32 & 6,28 & 71,95 \\
\hline $\begin{array}{l}\text { Cobertura Vegetal } \\
\text { Herbácea-arbustiva }\end{array}$ & 1.259 & 125.900 & 0,12 & 2,45 & 28,05 \\
\hline
\end{tabular}


Estima-se que para alcançar um adequado balanço térmico nas cidades é necessário que se tenha um índice de cobertura vegetal de cerca de 30\% (OKE, 1973 apud NUCCI, 2008). Desse modo pode-se considerar que a porcentagem obtida pela quantificação da cobertura vegetal no Distrito do Cambuci está bem abaixo do recomendado, interferindo assim em sua qualidade ambiental.

Com esses dados, foi possível considerar que o distrito do Cambuci apresenta problemas de qualidade ambiental. Segundo Gomes e Soares (2004) a qualidade do meio ambiente é considerada um fator determinante para que haja uma melhor qualidade de vida. Para um espaço urbano apresentar qualidade ambiental satisfatória é imprescindível uma composição paisagística que privilegie a vegetação tanto de simples gramados como de espécies arbóreas (GOMES e SOARES, 2004).

Conforme a configuração de distribuição vegetal proposta por JIM (1989), com a análise do mapa (Figura 06) foi possível encaixar a vegetação do distrito em dois subtipos do tipo geral "isolated" e em um subtipo do tipo geral "linear". Verificou-se também intensa fragmentação da vegetação em relação ao conjunto, predominando uma configuração desproporcional e descontinua e, portanto, caracterizada por maior aglomeração da vegetação em pequenas áreas e ausência de vegetação em grandes regiões.

Foram destacadas algumas áreas do subtipo "clumped" (isolated) com alguns agrupamentos de árvores dispersos na área do Distrito, uma área de configuração do subtipo "rectlinear" (linear) com pequena vegetação estreita, porém a configuração "dispersed" (isolated) foi a mais encontrada, caracterizando as falhas de vegetação ao longo do Distrito composto somente de árvores solitárias.

Foi possível destacar um local de maior concentração de cobertura vegetal, caracterizado por uma vegetação arbórea mais contínua. De acordo com a proposta de Jim (1989) foi encontrado o subtipo "clumped" com alta concentração de vegetação.

Localizado na porção centro-leste do distrito, na Rua Independência, onde se encontra o Comando do Exército do Sudeste, local de funcionamento do quartel e Hotel de Trânsito do Hospital Geral de São Paulo, com $92.300 \mathrm{~m}^{2}$ de cobertura vegetal tanto arbórea quanto herbáceo-arbustiva, representa aproximadamente $20 \%$ da cobertura 
vegetal do distrito. É um local bem arborizado onde funciona um hospital e unidades habitacionais, com algumas quadras de esporte, e grande área de lazer (MINISTÉRIO DA DEFESA - Disponível em: http://www.cmse.eb.mil.br/index.php/meios-dehospedagem/cambuci.html. Acesso em: 30 de Setembro de 2012).

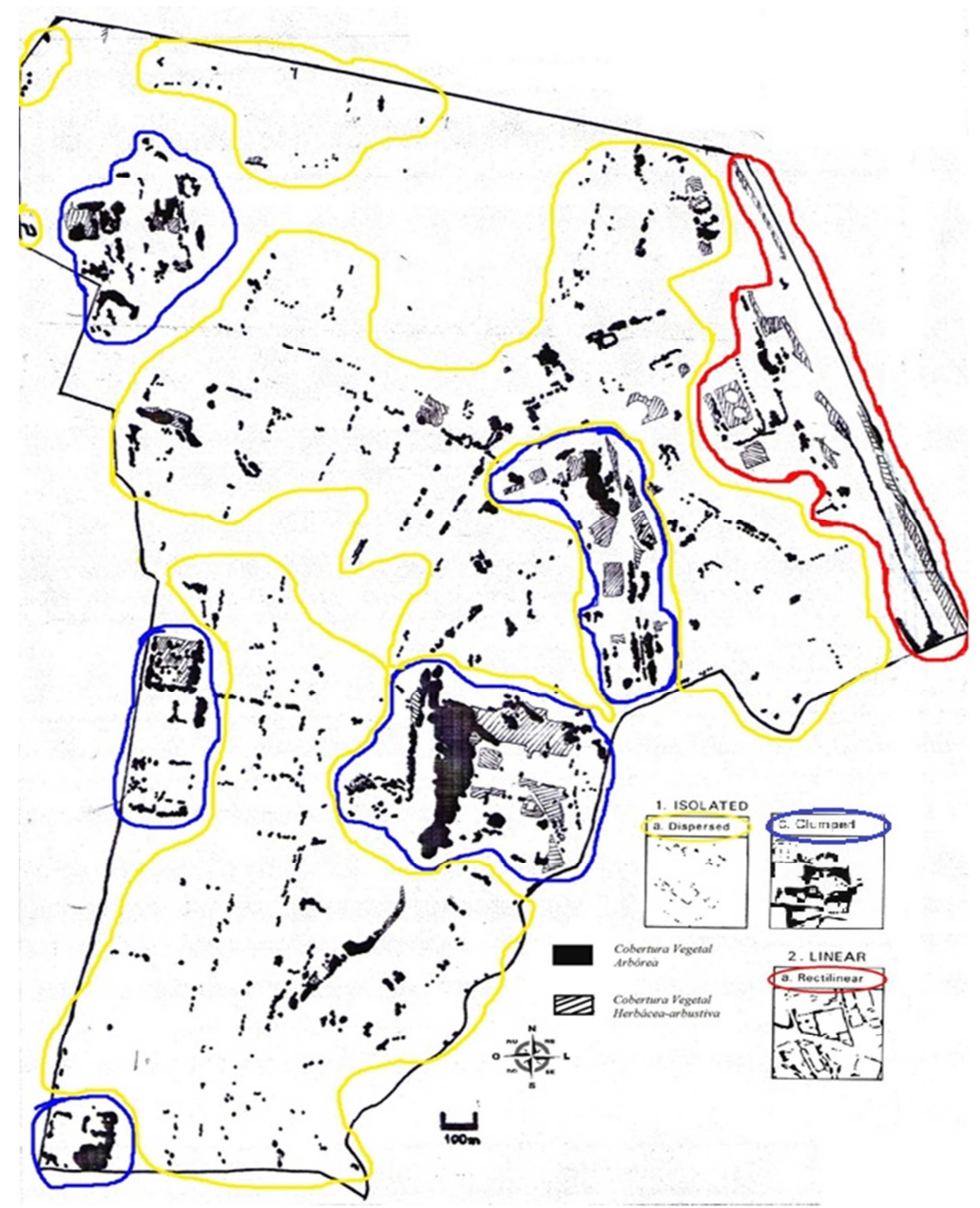

Figura 03 - Mapa da Cobertura Vegetal do Distrito do Cambuci - Centro de São Paulo/SP (Org.: GOMES, 2012)

$\mathrm{Na}$ porção oeste do distrito foi encontrado mais uma mancha com distribuição "clumped". A área corresponde a $20.800 \mathrm{~m}^{2}$ de cobertura vegetal e é constituída tanto por vegetação arbórea como herbáceo-arbustiva. Essa mesma área foi utilizada para a ocupação de um grande condomínio residencial com três torres. Apesar do condomínio 


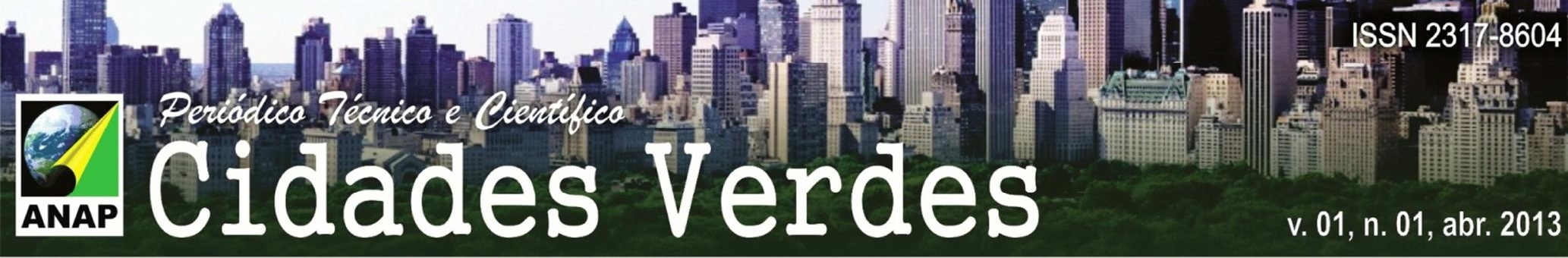

ainda apresentar intensa arborização, a área de cobertura vegetal diminuiu com as novas construções.

Porém o distrito apresenta algumas áreas onde quase não há vegetação, como na área norte próximo à Rua da Mooca e na área sudeste próximo à Rua Clímaco Barbosa. Segundo Lombardo (1985 apud NUCCI, 2008) áreas com até 5\% de cobertura vegetal são consideradas "desertos florísticos". A vegetação pode trazer benefícios ao ser humano, e lugares com pouca vegetação reflete uma qualidade ambiental não adequada às necessidades da população. Do mesmo modo não se pode afirmar que índices ligeiramente acima de $5 \%$ de vegetação são suficientes para a qualidade ambiental adequada (NUCCl, 2008).

Locais destinados ao lazer constituídos por espaços urbanos livres que a população utiliza para recreação, entretenimento e descanso, são denominados espaços livres de construção (NUCCI e CAVALHEIRO, 1999). Esses locais podem apresentar vegetação, contribuindo para o total da cobertura vegetal do distrito, como na Praça Olga BulgarelliD’áuria, Praça José Vicente Nobrega e Praça Hélio Ansaldo, e o Largo do Cambuci, considerado o coração comercial do bairro, que mesmo não apresentando uma adequada arborização, apresenta algumas árvores dispersas.

Áreas verdes são espaços livres constituídos principalmente por vegetação, com responsabilidade ecológico-ambiental, estético e de lazer (NUCCI e CAVALHEIRO, 1999). Os parques urbanos podem ser considerados áreas verdes, e são importantes estratégias para uma qualidade de vida no processo de crescimento urbano (CHIESURA, 2003). Algumas pesquisas atuais sobre o uso de parques urbanos constataram uma influencia dessas áreas verdes sobre a redução do stress urbano e benefícios para a saúde mental (HARTIG et al., 1991; CONWAY, 2000 apud CHIESURA, 2003). Apesar da grande importância de parques como áreas verdes, o distrito do Cambuci não apresentou locais com essas características, devido à acelerada urbanização priorizando a construção de edifícios e intensa pavimentação.

A composição da cobertura vegetal do distrito tem grande contribuição de vegetações de jardins de propriedades privadas, da arborização de ruas e de rotatórias. Segundo Nucci e Cavalheiro (1999) essa vegetação é considerada "verde de 
acompanhamento viário". Foram os componentes mais verificados ao longo do distrito, com vegetação escassa e dispersa. Foi adotado o subtipo "dispersed" como configuração da cobertura vegetal desses locais, sendo identificados no mapa pelos pequenos pontos isolados ao longo da área total.

Esse tipo de características de cobertura vegetal é comum em boa parte da área central das grandes cidades como São Paulo. Já em áreas distantes dos centros, como Alphaville e Tamboré (SP) (VENTURA e FÁVERO, 2005) e Santa Felicidade (Curitiba-SC) (MOURA e NUCCI, 2008), onde também foram realizados trabalhos de mapeamento e quantificação de cobertura vegetal, pode-se evidenciar um contexto diferente caracterizando coberturas vegetais bem mais significativas em quantidade e mais contínuas.

A comparação entre estudos da cobertura vegetal de diferentes locais pode ser observada nas tabelas 02 (em relação a quantificação da cobertura) e quadro 01 (em relação a distribuição predominante da cobertura).

Tabela 02 - Índices de cobertura vegetal de diversos estudos de cobertura vegetal (utilizando metodologias e escalas semelhantes à deste trabalho) para comparação.

\begin{tabular}{cccc}
\hline Referência do Estudo & Localidade & Escala & $\begin{array}{c}\text { Cobertura } \\
\text { Vegetal (\%) }\end{array}$ \\
\hline Estudo Atual & Distrito de Cambuci (MSP/SP) & $1: 10.000$ & 8,64 \\
\hline Maldonado (2010) & $\begin{array}{c}\text { Distrito do Bom Retiro } \\
\text { (MSP/SP) }\end{array}$ & $1: 10.000$ & 9,71 \\
Liang (2009) & Distrito da Liberdade (MSP/SP) & $1: 10.000$ & 8,08 \\
Buitron (2008) & Distrito da bela Vista (MSP/SP) & $1: 10.000$ & 9,02 \\
Nunes et al. (2008) & Distrito da Sé (MSP/SP) & $1: 10.000$ & 6,97 \\
Nucci (2001) & Distrito da Santa Cecília & $1: 10.000$ & 7,00 \\
\hline (Mdas e Fávero (2008) & Distrito da República (MSP/SP) & $1: 10.000$ & 8,76 \\
\hline
\end{tabular}




\begin{tabular}{|c|c|c|c|}
\hline Lopes e Fávero (2006) & $\begin{array}{c}\text { Distrito da Consolação } \\
(\mathrm{MSP} / \mathrm{SP})\end{array}$ & 1: 10.000 & 26,90 \\
\hline Ventura e Fávero (2005) & $\begin{array}{c}\text { Alphaville e Tamboré (Santana } \\
\text { do Parnaíba/SP) }\end{array}$ & 1: 10.000 & 66,20 \\
\hline Buccheri Fo. e Nucci (2005) & Bairro Alto do XV (Curitiba/PR) & 1: 10.000 & 16,85 \\
\hline Moura e Nucci (2008) & $\begin{array}{l}\text { Bairro Santa Felicidade } \\
\text { (Curitiba/PR) }\end{array}$ & 1: 10.000 & 42,29 \\
\hline Nucciet. al (2003) & Centro de Curitiba (PR) & $1: 8.000$ & 12,56 \\
\hline Dalbem e Nucci (2006) & São Braz (Curitiba - PR) & $1: 8.000$ & $50,47 \%$ \\
\hline Ito (2001) & $\begin{array}{l}\text { Bairro Jardim Tranquilidade } \\
\text { (Guarulhos/SP) }\end{array}$ & $1: 6.000$ & 4,00 \\
\hline
\end{tabular}

Quadro 01 - Comparação entre a classificação da distribuição das coberturas vegetais dos Distritos do centro de São Paulo.

$\begin{array}{ccc}\begin{array}{c}\text { Localização } \\ \text { Cambuci -SP }\end{array} & \text { Referência } & \begin{array}{c}\text { Classificação Predominante (tipo - } \\ \text { subtipo da proposta de Jim, 1989) }\end{array} \\ \text { Bom Retiro - SP } & \text { Maldonado (2010) } & \text { Isolated - Dispersed } \\ \text { Liberdade - SP } & \text { Liang (2009) } & \text { Isolated - Dispersed } \\ \text { Bela Vista - SP } & \text { Buitron (2008) } & \text { Isolated - Dispersed } \\ \text { Sé - SP } & \text { Nunes et al. (2008) } & \text { Isolated-Clumped } \\ \text { República - SP } & \text { Adas e Fávero (2008) } & \text { Isolated-Dispersed } \\ \text { Consolação - SP } & \text { Lopes e Fávero (2006) } & \text { Isolated-Clustered } \\ \text { Alphaville e Tamboré } & \text { Ventura e Fávero (2005) } & \text { Connected-Continuous } \\ \text { Santa Felicidade } & \text { Moura e Nucci (2008) } & \text { Connected }\end{array}$




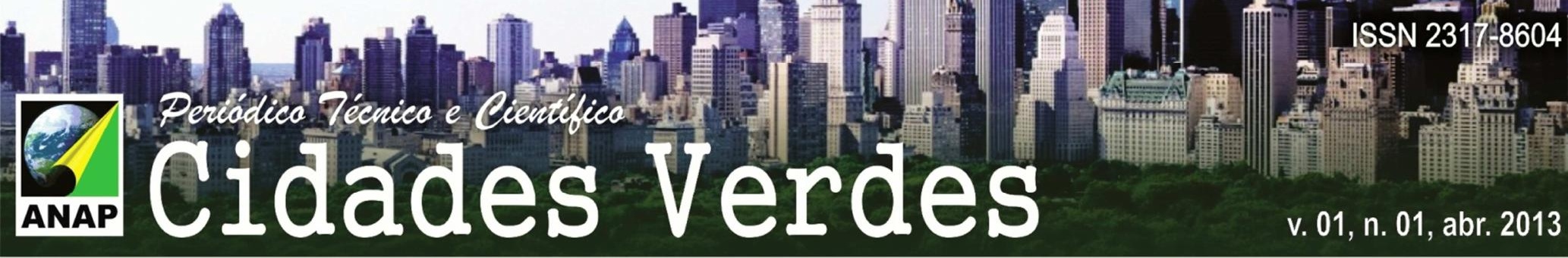

Com relação à Tabela 02, compara-se os distritos do centro de São Paulo. Verifica-se que, exceto o Distrito da Consolação, suas percentagens de cobertura vegetal ficam no intervalo de $6 \%$ a $9 \%$, e o Centro de Curitiba com $12,5 \%$, portanto não apresentam grandes diferenças na quantidade da cobertura, apesar de Curitiba ter a fama de ser uma das cidades com os maiores índices de vegetação dentre as cidades brasileiras (MOURA e NUCCl, 2008). Já na configuração da cobertura vegetal [considerando que todos adotaram a proposta de Jim (1989) como referencial], enfatizase a alta frequência do tipo "isolated" caracterizando intensa fragmentação vegetal em todas as áreas do centro de São Paulo (quadro 01).

Em contrapartida, em locais afastados do centro como Alphaville - Tamboré em São Paulo e no Bairro de Santa Felicidade, em Curitiba, verificou-se alta frequência do tipo "connected" na distribuição da cobertura vegetal, uma configuração de vegetação mais abundante e contínua, predominantemente áreas contendo espécies arbóreas. No que tange ao ICV além destes dois locais destaca-se também o Bairro São Braz, também afastado do centro de Curitiba, todos com ICVs bem maiores do que as áreas centrais.

Em contraponto ao índice de cobertura vegetal de Alphaville, o estudo de cobertura vegetal do Bairro Jd. Tranquilidade em Guarulhos apresentou um baixo ICV de $4 \%$, demonstrando o pior índice de cobertura vegetal dos estudos citados, trazendo uma baixa qualidade ambiental e de vida, apesar de se localizar afastado do centro da cidade (ITO, 2001).

Deste modo, é possível considerar que a localização, a densidade demográfica e o planejamento de urbanização distinto entre eles, são fatores importantes para entender a diferença de quantidade e configuração da vegetação, e todos esses fatores influenciam a qualidade de vida e ambiental.

Segundo Adas e Fávero (2008) baixos índices de cobertura vegetal (como no Distrito do Cambuci) se devem ao uso do solo com interesse de urbanização que desconsidera os elementos da natureza, principalmente a vegetação.

\section{CONCLUSÕES}


Com o mapeamento e a caracterização da cobertura vegetal do Distrito do Cambuci, obteve-se um total de $448.700 \mathrm{~m}^{2}$ de cobertura vegetal que correspondem a 8,64\% da área total ICV considerado o Índice de Cobertura Vegetal muito inferior ao de $30 \%$ recomendado pela literatura pertinente para manter uma qualidade ambiental adequada e consequentemente uma melhoria na qualidade de vida da população da área.

Considerando a configuração da cobertura vegetal total, verificou-se a presença de 3 subtipos da classificação proposta por Jim (1989): Isolated/Dispersed ao longo do distrito, Linear/ Rectilinear localizado na porção Nordeste, e Isolated/ Clumped sendo encontrado a Noroeste, Centro-oeste, Centro-leste e Sudoeste.

O Cambuci corresponde a uma área urbanizada antiga na cidade de São Paulo, onde o planejamento não priorizou a conservação da vegetação. Desse modo, este distrito se caracteriza por baixa frequência de vegetação contínua e predomínio de vegetação do tipo "isolated". Apresenta vegetação bem fragmentada interferindo negativamente em sua qualidade ambiental.

Importante ressaltar que grande parte da cobertura vegetal é composta por jardins de propriedades privadas, poucas praças e algumas árvores de calçada e no distrito há poucos locais considerados "áreas verdes" como parques com responsabilidade ecológico-ambiental e lazer, prejudicando assim a biodiversidade na área.

Com os resultados obtidos e a comparação com outras localidades, foi destacada a semelhança entre os distritos do centro da cidade tanto no índice de cobertura vegetal quanto na configuração da distribuição da vegetação. Cambuci obteve diferença com localidades longe do centro, onde apresentam maior vegetação.

\section{REFERÊNCIAS}

ADAS, M. A. A, FÁVERO, O. A. Estudo da Cobertura Vegetal do Subdistrito da República (Centro do Município de São Paulo/SP). Geografia. Ensino \& Pesquisa, 2008, v. 12, p. 2.850 - 2.863

BUITRON, L. M. Estudo de Cobertura Vegetal do Subdistrito da Bela Vista, Distrito Centro do Município de São Paulo/SP. Monografia de Conclusão de Curso apresentada ao Centro de Ciências Biológicas e da Saúde da UPM, 2008. 
BUCCHERI FILHO, A. T.; NUCCI, J. C. Espaços Livres, Áreas Verdes e Cobertura Vegetal no Bairro Alto da XV, Curitiba/PR. Revista do Departamento de Geografia, v. 18, p.48-59, 2006.

CAVALHEIRO, F.; NUCCI, J. C.; GUZZO, P.; ROCHA, Y. T. "Proposição de Terminologia para o Verde Urbano". Boletim informativo da SBAU (Sociedade Brasileira de Arborização Urbana), ano VII, n.3,Rio de Janeiro, p.7 - Jul/Ago/Set de 1999.

CHIESURA, A.The role of urban parks for the sustainable city.Elsevier - Landscape and urban Planning.Netherlandsv. 68, 2004 p. $129-138$.

DALBEM, R. P.; NUCCI, J. C. Cobertura Vegetal: Conceituação, classificação e quantificação aplicadas ao bairro São Braz, município de Curitiba - PR. In: IV Seminário Latinoamericano de Geografia Física, 2006, Maringá, Anais. Maringá/PR, Universidade Estadual de Maringá, 2006.

FREITAS, K. M.; LOMBARDO, M. A. Índices Urbanísticos e Qualidade Ambiental em Áreas Centrais de Metrópoles: o caso de São Paulo. Mercator - Revista de Geografia da UFC, número 12, Rio Claro, p. 69 81, 2008.

GOMES, M. A. S. e SOARES, B. R.. Reflexões sobre a qualidade ambiental urbana. Estudos Geográficos: Revista Eletrônica de Geografia, Rio Claro, 2(2): 21-30, Jul - Dez - 2004.

ITO, K. M. Cobertura Vegetal do Bairro Jardim Tranquilidade no Município de Guarulhos/SP. 2001. 31f. Monografia de Conclusão de Curso (bacharelado) - Faculdade Integrada de Guarulhos, Guarulhos, 2001.

JIM, C. Y. (1989) "Tree-canopy characteristics and urban development in Hong Kong".Geographical Review, v. 79, n.2, New York: American Geographical Society, april 1989. 210-225 p.

LIANG, B. ESTUDO DA COBERTURA VEGETAL DO SUBDISTRITO DA LIBERDADE (DISTRITO CENTRO DE SÃO PAULO/SP). 2009. 51f. Monografia de Conclusão de Curso apresentada ao Centro de Ciências Biológicas e da Saúde da UPM, São Paulo - SP.

LOBODA, C. R.; DE ANGELIS, B. L. D. Áreas Verdes Públicas Urbanas: Conceitos, Usos e Funções.

Revista do Centro de Ciências Agrárias e Ambientais v. 1 n. 1. 2005.p. 125-139. Disponível em:http://revistas.unicentro.br/index.php/ambiencia/article/view/157/185. Acesso em: 3 de abril de 2012.

LOPES, B. J. ESTUDO DA COBERTURA VEGETAL DO SUBDISTRITO DA CONSOLAÇÃO (MSP/SP).2005. 52f. Monografia de Conclusão de Curso apresentada ao Centro de Ciências Biológicas e da Saúde da UPM, São Paulo.

MALDONADO, L. F.; Mapeamento e Avaliação da Cobertura Vegetal do Distrito do Bom Retiro (Centro de São Paulo/SP). 2010, 46 f. Monografia de Conclusão de Curso apresentada ao Centro de Ciências Biológicas e da Saúde da UPM, São Paulo.

MINISTÉRIO da Defesa. Exército Brasileiro - Comando Militar do Sudeste (CMSE). Disponível em: http://www.cmse.eb.mil.br/index.php/meios-de-hospedagem/cambuci.html. Acesso em: 30 de Setembro de 2012. 
MOURA, A. R.; NUCCI, J. C. Cobertura Vegetal em áreas urbanas - O caso do Bairro de Santa Felicidade Curitiba - PR, Geografia. Ensino \& Pesquisa. Santa Maria: UFSM, 2008. 1682-1698 p.

$\mathrm{NUCCI}$, J. C. Análise sistêmica do ambiente urbano, adensamento e qualidade ambiental. PUC/SP. Ciências Biológicas e do Ambiente, São Paulo, v.1, n.1, p. 73-88, 1999.

$\mathrm{NUCCI}$, J. C. Qualidade ambiental e adensamento urbano - Um estudo de ecologia e planejamento da paisagem aplicada ao distrito de Santa Cecília. 2ª Ed. - Curitiba: O Autor, 2008. 150p. ISBN 978-85908251-0-4

NUCCI, J. C.; CAVALHEIRO, F. Cobertura Vegetal em áreas urbanas: conceito e método. GEOUSP, N.6, P. 29-36, 1999.

NUCCI, J. C.; WESTPHALEN, L. A.; BUCCHERI FILHO, A. T.; NEVER, D. L.; OLIVEIRA, F. A. H. D.; KROKER, R. Cobertura Vegetal no Bairro Centro de Curitiba, Rio de Janeiro: Revista GEOUERJ, n especial, Nov. 2003.

NUNES, T. C. F., LOBO, R. S. V., MARQUES, T. C. C., FÁVERO, O. A. Estudo da Cobertura Vegetal do Subdistrito da Sé, Centro de São Paulo/SP. Geografia. Ensino \& Pesquisa, v.12, p. 1753 - 1766, 2008.

PINOTTI, H. W; O Cambuci Outrora e Agora - São Paulo: Editora do Autor, 1르 edição, 2006. p. 295.

PONCIANO, L; Bairros Paulistanos de A a Z - São Paulo: Editora SENAC São Paulo. $2^{\mathrm{a}}$ edição revista, 2002.p. 275.

SCHMIDT, E.; BUCCHERI FILHO, A. T.; KROKER, R.; NUCCI, J. C. Método para o Mapeamento da Qualidade Ambiental Urbana. In: XI Simpósio Brasileiro de Geografia Física Aplicada, Setembro de 2005, São Paulo, Anais. São Paulo: USP, 2005. p. $393-404$.

SCHWETS, T.; BROWN, R. D.From and structure of maple trees in urban Environments. Elsevier LandscapeandUrban Planning. Canadá, v. 46, 2000, p. $191-201$.

Secretaria Municipal de Coordenação das Subprefeituras - Dados Demográficos dos Distritos pertencentes às Subprefeituras. Disponível em:

http://www.prefeitura.sp.gov.br/cidade/secretarias/subprefeituras/subprefeituras/dados demograficos/index. php? $\mathrm{p}=12758$. Acesso em: 02 de Setembro de 2012.

TAKIYA, H. Atlas Ambiental do Município de São Paulo - Relatório Final. Secretaria Municipal do Verde e Meio Ambiente (SVMA) e Secretaria Municipal do Planejamento Urbano (SEMPLA), v.1, 203p. jul. 2002. TAKYIA.

VENTURA, T. B.; FÁVERO, O. A. Estudo da Cobertura Vegetal dos Bairros de Alphaville e Tamboré (Santana de Parnaíba/SP). In: XI Simpósio Brasileiro de Geografia Física Aplicada, Setembro de 2005, São Paulo, Anais. São Paulo: USP, 2005, p. 784-797. 